\title{
Exploring the Twitterland of the Impact Investing Market
}

\author{
Petra Kralj Novak ${ }^{1(\bowtie)}$, Luisa De Amicis², Catherine Hughes ${ }^{2}$, \\ and Igor Mozetič ${ }^{1}$ \\ 1 Department of Knowledge Technologies, Jožef Stefan Institute, \\ Jamova cesta 39, 1000 Ljubljana, Slovenia \\ petra.kralj.novak@ijs.si \\ 2 PlusValue, Collective Temperance, 110 Hampstead Road, \\ London NW1 2LS, UK
}

\begin{abstract}
Whilst impact investing has recently exhibited exceptionally high growth rates, creating an interconnected and functioning market remains an open challenge. Social media play an increasingly important role in understanding communication and relations between different players in the market. This is the first time that network, content, and sentiment analysis have been applied to impact investing, to the best of the authors' knowledge. In the paper, we explore the Twitter activities of 83,012 Twitter users in this field over a period of four months. We analyze Twitter sentiment w.r.t. related topics, identify influential Twitter users, and detect retweet communities. We characterize the communities in terms of influential users they comprise, hashtags they use, and how they relate to typical categories of actors in this domain (investors, social businesses,...). Despite policy makers' effort, we find out that more awareness has to be raised about the topic and the market is not so cohesive yet. The role of tech industry is also discussed. We provide recommendations for a more conducive environment to make the market flourish.
\end{abstract}

\section{Introduction}

The term impact investing was coined in 2007, when the Rockefeller Foundation invited leaders in finance, philanthropy and development to discuss the need for a global industry striving for investments with positive environmental, social, and governance (ESG) impacts [6]. In recent years, more policy makers, traditional investors, investees, and not-for-profit organisations have become aware of this term and have been willing to approach this new world with growing interest, basic curiosity, and occasionally cautious skepticism. Boosted by these new supporters, the market has experienced very high growth rates, with the Global Impact Investing Network (GIIN) estimating that the impact investing sector has grown from $\$ 4.3$ billion in 2011 to $\$ 60$ billion in 2015 , with the amount invested by the 125 leading impact investors forecast to grow by nearly $20 \%$ per year [12]. In the US, investments focused on sustainable, responsible, or impact investing 
strategies, accounted for one out of every 6 dollars under professional management in 2014, representing a total value of $\$ 6.57$ trillion and a 2-year growth rate of $76 \%$ [10]. In Europe, Eurosif (the pan-European sustainable and responsible investment membership organization) estimates that the total impact investing market has grown from €8.75 billion in 2011 to $€ 20.27$ billion in 2013.

Whilst the growing relevance of impact investing is undeniable, no agreement has been reached on its exact definition. According to Eurosif [2], impact investing consists of investments made into companies, organisations, and funds with the intention to generate social and environmental impact alongside a financial return. This is the working definition we use for this paper. Impact investment can be made in both emerging and developed markets, and target a range of returns from below market to market rates, depending upon the circumstances. In the "investment spectrum" ranging from traditional finance-only investment to traditional impact-only philanthropy, impact investing represents the new paradigm in the middle that includes responsible, sustainable, thematic, and impact-first types of impact investment, as schematically presented in Fig. 1.

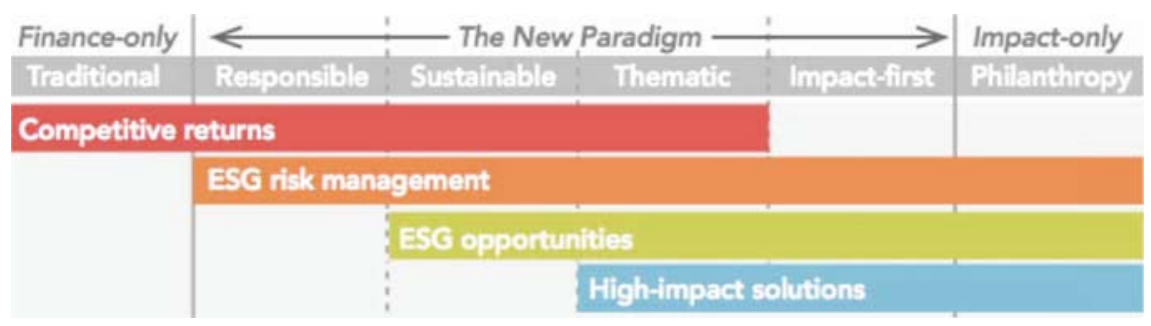

Fig. 1. The impact investment spectrum (adapted from http://theimpactengine.com/ the-spectrum-of-impact-investing/).

Despite the multiple definitions, policy makers, entrepreneurs, investors across the sector have acknowledged the importance of creating an interconnected and functioning market if impact investing is to work. Progress has been made, but still there are issues both on the demand and the supply side of the market.

In the paper, we explore the Twitter activities of different impact investing players. The goal is to analyze their presence and activities on Twitter, to understand:

- if one can talk about a market for impact investing, which is existing and significant on social media (and its relations to mainstream media);

- if the market is really cohesive, with the different categories (i.e. investors, social enterprises, policy makers, etc., see Table 2) interacting within each category and with other categories;

- what are the most important topics for the impact investing market and what are the key influencers and their communities. 
We use Twitter as a proxy of the impact investing market and we provide recommendations on how to strengthen the ecosystem and raise awareness about it in order to establish impact investing as the new standard.

\section{Twitter Volume and Sentiment}

We collected a corpus of relevant tweets in the period from March 28, 2017 to July 12, 2017 through the Twitter Search API. We started with an initial list of known impact investing Twitter users and a list of Twitter hashtags, and used them as queries to get a comprehensive coverage of the impact investing market. The queries include some relevant users (@YF_Academy, @esmeefairbairn, @resonanceltd, @Big PotentialSI, etc.), single hashtags (\#socfin, \#impinv \#socialfinance, \#impactinvestment, etc.), combined hashtags (\#social \& \#finance, \#social \& \#investment, \#impact \& \#assessment, etc.), and hashtags of major impact investing events (\#impact2, \#socap17, \#OxfordIIP, \#skollwf, etc.).

The dataset includes 234,243 tweets over a period of 106 days, i.e., on average there are about 2,200 tweets per day (Fig. 2). The number of distinct Twitter users in the analyzed dataset is 83,012 .

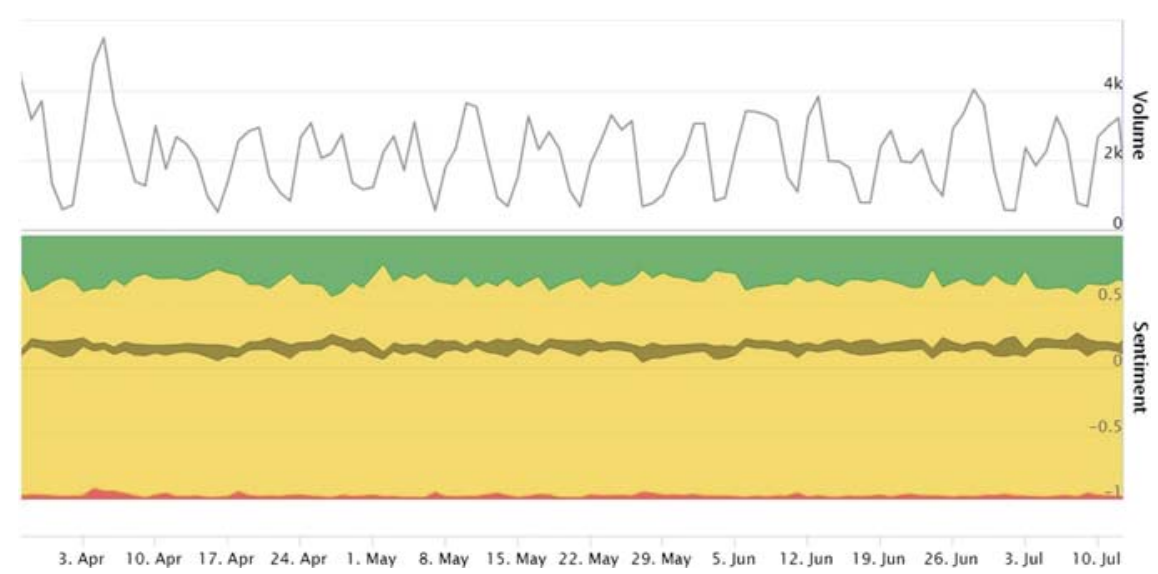

Fig. 2. Volume and sentiment of collected tweets. The top chart shows the daily volume of the tweets acquired, while the bottom chart shows the aggregated sentiment of tweets. Sentiment is computed from a general purpose English sentiment model: positive sentiment is in green, neutral sentiment in yellow, negative sentiment in red, and the mean sentiment score is in gray.

A general purpose English tweets sentiment analysis model [11] was applied to the corpus to get an overview of the sentiment polarity and subjectivity in the dataset. The results are shown in the lower part of Fig. 2 as aggregated sentiment scores of tweets per day. The majority of the tweets are neutral. However, 
the subjective tweets (non-neutral) are predominantly positive and the mean sentiment score (grey line) is also positive. This means that most of the people that tweet about impact investing do not have strong feelings about it, but the majority of those who do have feelings tend to have positive ones.

The fact that most of the tweets are neutral is in line with the fact that most of the tweets are during the workdays and are mainly used to share information and links of relevant resources. As for the mostly positive subjective tweets, this came as a surprise if compared to previous sentiment analysis experiments specifically focusing on environmental topics. In [15] we showed that different communities have very different sentiment leanings towards e.g. climate change on the one hand, and oil, gas and fracking on the other hand.

\section{Influential Twitter Users}

We consider retweeting as one of the most relevant activities for information diffusion on Twitter. We analyze two aspects of retweeting activities. First, we measure the social influence of Twitter users in terms of their posting activity and ability to engage their followers for support (i.e., by retweeting their posts). Second, we construct a retweet network where Twitter users are linked when they retweet each other. We detect the largest communities in the network and the role of the influential users in them.

We adapt the Hirsch index ( $h$-index) [5] to rank the Twitter users by social influence. The $h$-index is a well-known author-level bibliometric indicator that quantifies the scientific output of a scholar by combining her/his productivity and citation impact. We adapt the $h$-index to Twitter data [4]: a Twitter user with an index of $h$ has posted $h$ tweets, each of which has been retweeted at least $h$ times. Let $R T$ be the function that corresponds to the number of retweets of each tweet. The values of $R T$ are ordered in decreasing order, from the largest to the lowest value, and $i$ corresponds to the position in the ordered list. The $h$-index is then computed as follows:

$$
h-i n d e x(R T)=\max _{i} \min (R T(i), i)
$$

A survey of influence measures on Twitter is given in [14]. Twitter $h$-index was already used as a measure of influence ([4], in [7] referred as T-index).

The top most influential Twitter users, with $h$-index above 10, are in Table 1. Each user is also assigned a category which designates different types of actors in impact investing. The categories were devised manually by experts from impact investing (see Table 2).

The most influential account is an individual, John Lloyd IV, who is the Chief Marketing Officer of Clearly So, followed by Clearly So itself. Johns h-index is 40 and he has more than 141,000 followers, whilst Clearly So's h-index is 36 and is followed by 18,400 accounts. The third most influential account is from Costa Rica (the only one from a non-English speaking country), four out of ten are from the US, whilst the remaining five are from the UK. This can be partially 
Table 1. Top influential Twitter users (with h-index above 10) along with their category and description.

\begin{tabular}{|c|c|c|c|}
\hline Twitter user & h-index & Category & Description \\
\hline @jalloyd4 & 40 & Practitioner & $\begin{array}{l}\text { John Lloyd IV, CMO of @ClearlySo, } \\
\text { Board Member of @eCadets }\end{array}$ \\
\hline @ClearlySo & 36 & Intermediary & $\begin{array}{l}\text { Raises capital, runs impact investing } \\
\text { network }\end{array}$ \\
\hline @IgnacioMls & 23 & Practitioner & Solving environmental and social issues \\
\hline$@$ GoldmanSachs & 17 & Investor & $\begin{array}{l}\text { Official Goldman Sachs Twitter } \\
\text { account }\end{array}$ \\
\hline @SchSocEnt & 16 & Social business & $\begin{array}{l}\text { School for Social Entrepreneurs, } \\
\text { charity that supports entrepreneurial } \\
\text { approaches }\end{array}$ \\
\hline @atlcelebrity & 14 & Practitioner & $\begin{array}{l}\text { Awesome Foundation Atlanta Chapter } \\
\text { Founder }\end{array}$ \\
\hline @SkollFoundation & 13 & Intermediary & $\begin{array}{l}\text { Investing and connecting social } \\
\text { entrepreneurs and innovators }\end{array}$ \\
\hline @darrenwalker & 11 & Practitioner & President of @FordFoundation \\
\hline @softgiving & 11 & Private company & $\begin{array}{l}\text { Supports options that fit people unique } \\
\text { lifestyle }\end{array}$ \\
\hline @SocialEnt_UK & 11 & Intermediary & $\begin{array}{l}\text { Social Enterprise UK is the member- } \\
\text { ship body for social enterprise }\end{array}$ \\
\hline
\end{tabular}

explained by the fact that all the queries have been made in English but equally by the fact that the UK and US share a leading position at global level in the impact investing field. The fourth most influential account is Goldman Sachs. As already stated, many 'traditional investors' (e.g. Goldman Sachs) are moving towards the impact investing field.

Surprisingly, neither public institutions nor universities appear on the list, despite them having a considerable vested interest in the sector. Media organisations and journalists are another group whose absence is noteworthy. There is only one social business among the most influential Twitter users, the School for Social Entrepreneurs, a charity that offers highly practical social enterprise courses. The Skoll Foundation is the only foundation included on the list, although the president of Ford foundation, Darren Walker is also included. The UK membership organisation for social enterprise is the 10th most relevant account. This account is followed by 48,975 users, indicating the presence of a market.

All the Twitter users with the h-index above 5 were selected for a more indepth analysis. The 170 influential Twitter users with h-index above 5 posted 19,353 tweets in the analyzed period, and were retweeted 38,804 times, accounting altogether for almost $25 \%$ of the whole dataset. In other words, $2 \%$ of the users account for $25 \%$ of the content. The 170 users were categorised according to the nature of the activities carried out. All the categories are listed in Table 2, showing Twitter user categories, the split across categories (in absolute numbers 
Table 2. Twitter user categories, the fraction of influential users (with $h$-index above 5 ) in each category, and its description.

\begin{tabular}{|c|c|c|}
\hline Category & $\begin{array}{l}\text { No. of influential } \\
\text { Twitter users }\end{array}$ & Description \\
\hline Investor & $12(7 \%)$ & Banks, funds, asset managers \\
\hline Social business & $13(8 \%)$ & $\begin{array}{l}\text { Any organisations with a social pur- } \\
\text { pose, such as NGOs, charities, vol- } \\
\text { untary and community organisa- } \\
\text { tions, social enterprises, community } \\
\text { interest companies (CIC) }\end{array}$ \\
\hline Practitioner & $46(27 \%)$ & $\begin{array}{l}\text { Individuals working for organisa- } \\
\text { tions active in the field, opinion } \\
\text { leaders }\end{array}$ \\
\hline Ad-hoc initiative & $13(8 \%)$ & $\begin{array}{l}\text { Activities relevant for the sector } \\
\text { with no legal status, such as one-off } \\
\text { funded projects, policy initiatives, } \\
\text { steering groups }\end{array}$ \\
\hline Intermediary & $57(33 \%)$ & $\begin{array}{l}\text { Any organizations that do not } \\
\text { tackle a social problem directly but } \\
\text { enable other players to do that, } \\
\text { such as Foundations, fairs, business } \\
\text { support hubs, national membership } \\
\text { bodies, platforms, networks }\end{array}$ \\
\hline Private company & $8(5 \%)$ & $\begin{array}{l}\text { For profit private companies exclud- } \\
\text { ing social enterprises }\end{array}$ \\
\hline Media & $10(6 \%)$ & $\begin{array}{l}\text { Magazines, blog, podcasts, journal- } \\
\text { ists }\end{array}$ \\
\hline Public sector & $4(2 \%)$ & $\begin{array}{l}\text { Local or national government, inter- } \\
\text { national institution }\end{array}$ \\
\hline Academia & $3(2 \%)$ & Universities, professors \\
\hline Other & $4(2 \%)$ & $\begin{array}{l}\text { Individuals doing something unre- } \\
\text { lated to the topic, political parties }\end{array}$ \\
\hline Total & $170(100 \%)$ & \\
\hline
\end{tabular}

and percentage) of the 170 most influential Twitter users (those with h-index above 5), and a description of each category:

- Social Business (8\% of users): Such a low figure may be due to the fact that an active social media presence is an investment, and these business may tend to focus on project delivery instead. Claiming to have a social purpose, they may be satisfied with their offline presence.

- Intermediaries (33\%): This is the largest category in this sample, perhaps indicating the presence of an online bubble where enablers have become more relevant than doers, or simply focus more on online community building. This 
observation has potential ramifications for policy makers' primary objectives, as the sector's primary online presence is not a direct reflection of end beneficiaries. How could the sector become more visible, if best practices are not shared widely?

- Academia (2\%): As many of the best universities have programmes on social enterprise, social innovation or impact investing, the weak online presence of these institutions comes as a surprise. This could indicate a missed opportunity to expand awareness of the impact investing market, connect demand and supply and strengthen skills, especially on the demand side of the market in order to absorb investment.

- Media (6\%): The sector-specificity of the media listed is the most noteworthy aspect of this group, with Emily Chasan from Bloomberg Brief (Sustainable Finance Editor) being the only representative of mainstream media (despite being the editor of a Brief with a very specific topic). This may illustrate the ongoing niche aspects of the sector as it struggles to become mainstream (despite the interest showed by many newspapers such as the Guardian or communication agencies such as Thomson Reuters) or simply may show that other media (social as Facebook of LinkedIn or more traditional ones) are preferred.

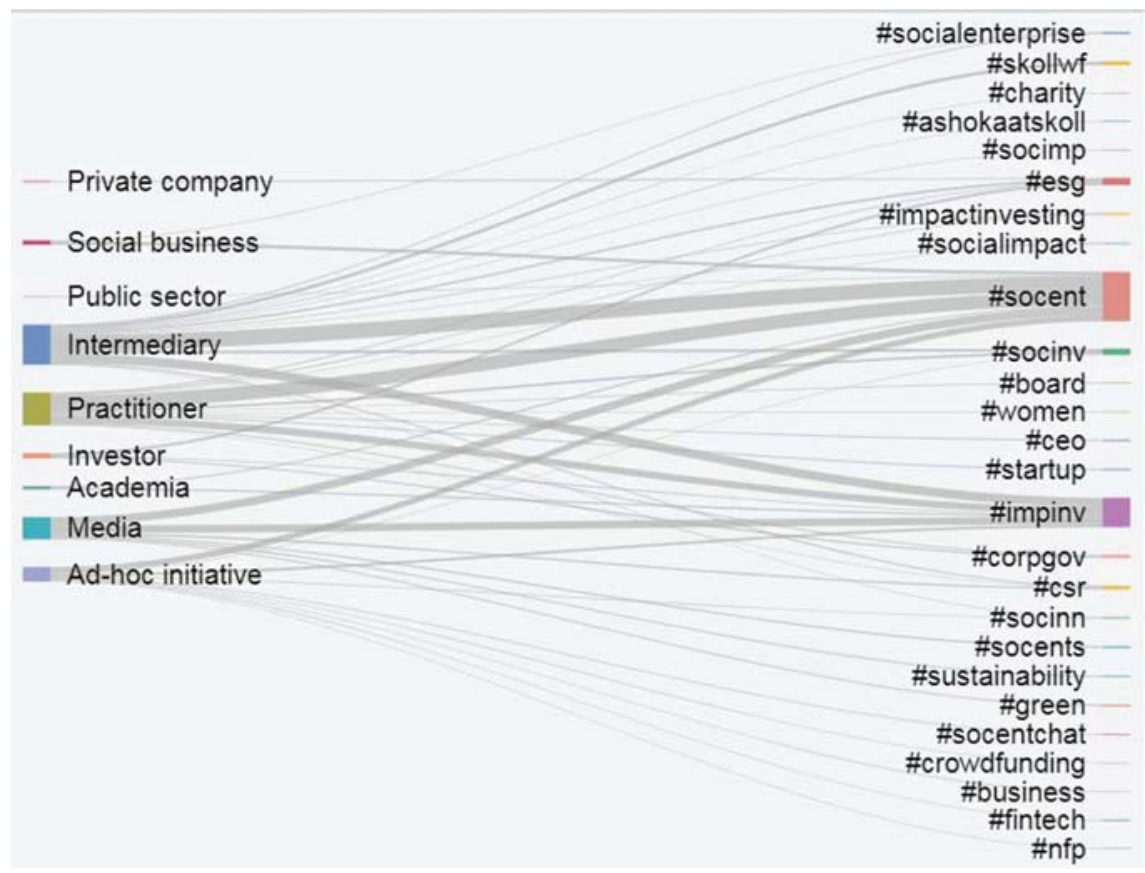

Fig. 3. The use of hashtags by the 170 influential users, grouped into ten categories (left-hand side). One the right-hand side are hashtags, each used at least 100 times. 
- Investor (7\%): It is an open question as to whether this low number is due to a relationship of few (investors) to many (investees), or because investors tend not to communicate publicly.

- Individuals (27\%): This is the second biggest group and includes mainly individuals that work in the sector (as CEO, founder, or in any other senior capacity) but tweet in their personal capacity.

The presence of categories like Ad-hoc Initiatives or Others shows that the sector is also getting outside attention, but is in general still poorly structured.

We also explore topics discussed by these categories (see Fig. 3). \#socent is by far the most popular hashtag, being tweeted by most of the categories except private companies and investors. \#impinv scores high for number of tweets, although social businesses, private companies and the public sector are not tweeting about it. Does this mean investors and investees are disconnected? Is there a role for policy makers in facilitating dialogue? Policy makers only talk about \#socent. Further studies and analyses will be needed in this regard. Private companies, poorly represented ( $5 \%$ of the sample, see Table 2 ) are tweeting exclusively about \#esg. Ad-hoc initiatives tweet about \#fintech and \#crowdfunding, showing some interdisciplinarity.

\section{Retweet Communities}

In complex networks, the notion of community corresponds to a subset of nodes that are more densely connected among themselves than with the other nodes. Several definitions of community and methods to detect them have been proposed, see [3] for a review. We apply a standard community detection algorithm, the Louvain method [1], to our retweet network. The method partitions the network nodes so that it maximizes the its modularity. Modularity is a measure of community density in a network: the fraction of edges falling within groups of a given network partitioning as compared to the expected fraction of edges in these groups, given a random distribution of links in the network [13]. Among the available community detection algorithms in the optimization-based class, the Louvain method is one of the few suitable: (i) to analyze large networks with good scalability and (ii) to avoid ex-ante assumptions on their size [8].

We have constructed a retweet network from the collected tweets. In the network, there are 56,930 Twitter users and 85,580 edges (retweets). When we apply the Louvain community detection we get ten communities with more than 1,000 users each (accounting for $54.8 \%$ of all the users and $64.0 \%$ users in the giant connected component). The detected community are presented in Fig. 4.

Figure 5 shows a bipartite network of retweet communities and hashtags. The retweet communities are denoted by colors (bottom-right inset) and named by the most influential users. Shown are hashtag used at least 100 times by each community. The central hashtags are used by all communities while the peripheral ones are specific for the community they are connected to. The key communities detected do not always correspond to the most influential accounts identified in Table 1. 


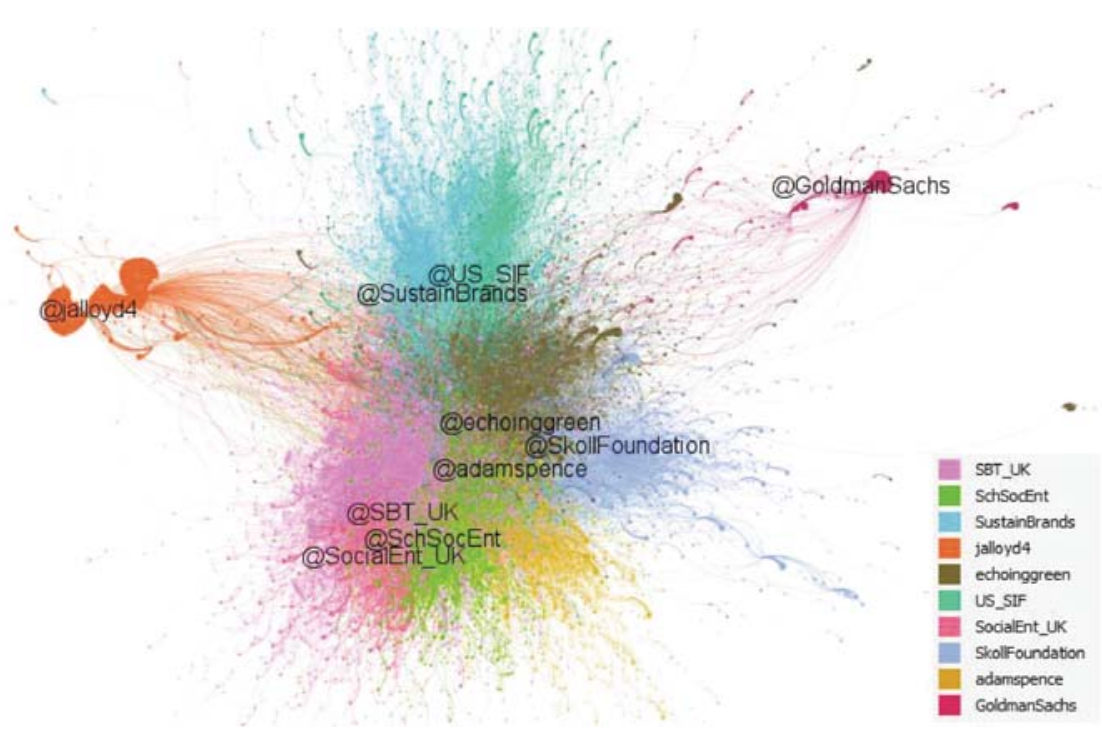

Fig. 4. Retweet communities with influential Twitter users.

As expected, the central hashtags are about impact investing and social enterprise. As for the peripheral communities, we can recognise three main patterns:

- Blue/green: Led by @US-SIF, the forum for sustainable and responsible investment, the community has a focus on \#climate and \#climatechange, including also related topics such as \#greenbonds, \#energy or \#sustinv.

- Red/orange: The community around John Lloyd IV, the CMO of Clearly So as well as the most influential account in the analysis, covers mainly topics relate to \#impinv, \#investment, \#investors and \#finance. \#millennials is also tweeted. We plan to run more analysis to understand the evolution of this hashtag.

- Between the green (@SchSocEnt) and violet community (led by @SBT_UK), there is a cloud of hashtags with a focus on entrepreneurship (i.e. \#socialentrepreneur, \# entrepreneruship \#socialchange). Fintech also appears in this group.

\#Tech is quite central in the network, whilst \#technology is between @SBT_UK and @echoinggreen, an organisation providing seed funding and leadership development to talents across the world. Interestingly, in Fig. 5 there is nothing related to governments or international institutions. There is also very little about education, developing capacity and skills. Looking at this results, one may wonder about the interest of the sector. Some of the most influential communities detected focus on this, although the content analysis tells us that 


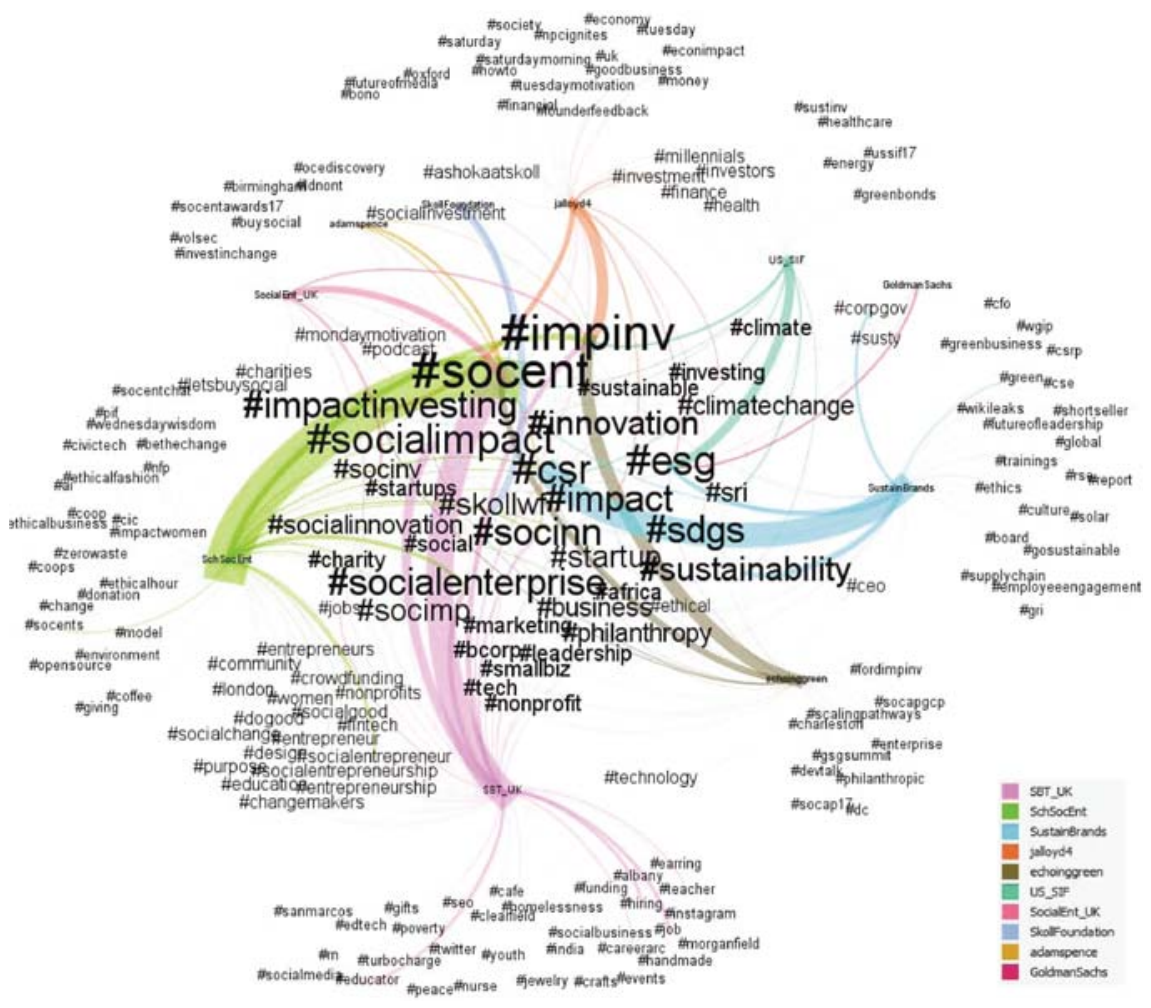

Fig. 5. A bipartite network of retweet communities and hashtags. The retweet communities are denoted by colors (bottom-right inset) and named by the most influential users. Shown are hashtag used at least 100 times.

these are not among the most popular hashtags. There is little about public procurement and impact measurement, which are usually expected to be the key topics in the sector.

Figure 6 presents a many-to-many mapping between the retweet communities (Fig. 4) to the user categories (Table 2). The intermediaries are distributes across all the communities (but the Goldman Sachs one) so are the practitioners (but the Goldman Sachs and the Skoll Foundations one). In contrast, the media users are present in three communities only. Investors are present in five communities, whilst social business only in three. Only two communities out of nine include both investors and social business, which holds well on the hypothesis that supply and demand are still too disconnected to make the market flourish. Goldman Sachs' community includes only investors, whilst we can find academia and public sector in the @echoingreen community only. The "other" user category is only in the Skoll Foundation. 


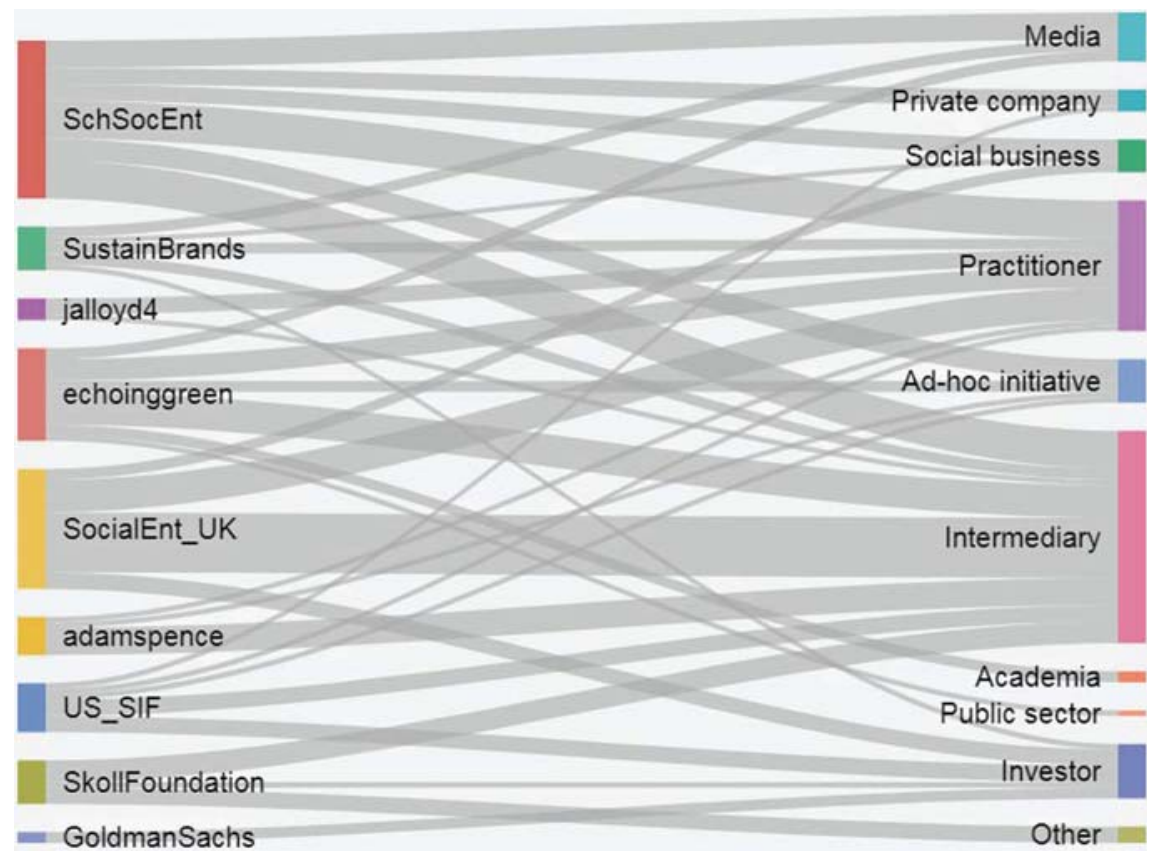

Fig. 6. Mapping of communities (left-hand side) to influential user categories (righthand side).

\section{Discussion and Conclusions}

In this paper, we analyse Twitter as a way to explore relationships between different categories of players operating within the impact investing ecosystem. Firstly, we point out that the number of tweets collected during the given period about impact investing (and related topics) is about 2,000/day. However, mainstream media journalists and bloggers are not among the influencers for the sector and this may mean that they do not write much on the topic as they are not interested in it or simply they think the topic will not sell enough. There is a saying in English that goes: "Good news doesn't sell (newspapers)". When a journalist writes about a success, a best practice or simply a nice story, people have the tendency not to read the article. On the contrary, when it is about war, scandals or suffering, people are eager to know more. This could be a reason for the lower-than-expected levels of media engagement with impact investing, as many of the stories coming from the sector are positive.

The awareness-raising activities as well as the information and knowledge sharing happening in the sector are fully in the hands of intermediaries and practitioners, the categories which are best connected across most of the communities. Policy makers are actively encouraging intermediaries to raise awareness about impact investing (i.e. Big Society Capital in the UK). Media should also be a target for policy makers if they really want the market to grow. The 
results of the sentiment analysis and the fact that most of the Twitter users are supportive of impact investing should on one side motivate journalists to cover more stories about this topic, and, on the other, push investors and social businesses to share positive news.

We also notice that different categories of players are not connected. Despite efforts to stimulate demand and supply, it is observed that social businesses, charities and community organisations do not interact in a significant way with investors, at least on social media (see Fig. 6). This is highly noteworthy, and emphasises the role of intermediaries and practitioners, the only categories facilitating dialogue between supply and demand. Even the topics they cover are different (see comment to Fig. 3). Dialogue with corporates is also weak, while the academic and the public sectors are almost absent. In order to reinforce the ecosystem, we welcome increasing interactions between the different stakeholder categories, through interdisciplinary events and forums for discussion. Some of these positive practices already exist, but there is a need for reinforcement.

Finally, technological companies (i.e. Atos, Bstow uk, TruValue Labs) or fintech (i.e. Impak finance, Impak Coin) are listed among the influential users. Often social businesses (especially the more traditional NGO sector) are seen as very far away from technological companies, however more recently we have observed two phenomena: (i) organisations or companies using technologies for good as in the case of Impak Coin (which could be particularly interesting as it is one of the first examples of using cryptocurrency in the sector), or (ii) proper forprofit companies as Atos identifying the social business sector as a new market to explore. Having tech companies working in the field of social business and impact investing is encouraging and shows how the sector is actually using technologies to achieve social impact. The presence of tech and fintech is also evident from the hashtags detected among the most influential communities. We welcome the relationship between tech and social businesses, and we encourage policy makers to develop more studies on this relationship. We are aware that the European Commission has already taken steps in this direction [9] but we believe that a more comprehensive analysis, both qualitative and quantitative, should be made.

This last point is directly connected with the rise of hybrid organizational models, especially in the social innovation, social enterprise, and impact investing space. This is not only intrinsic to the sector (and in its final purpose of aligning public and private interests), but is also evident from the fact that it was difficult to categorize the users (basically, the traditional classifications of public, private and third sector do not always apply).

This paper represents the first attempt to apply sentiment, network and content analysis to the impact investing ecosystem, to the best of authors' knowledge. More research should be carried out both on the demand and the supply side. First of all, the Twitter analysis can be extended to different languages, in order to gain further insights on the global scene. We can also consider expanding the analysis to other social media (i.e. Facebook or Linked-in), or replicate the analysis the next year to see how the sector is evolving. By jointly analyzing local national and international policies and social media, we understand 
the impact created by these policies, especially if we focus on one specific country. Further experiments will be carried out to understand whether citizens are aware of the impact investing market and what could motivate them to invest in impact funds. On the supply side, we want to understand what are the key impact investing funds and what are the drivers for them to invest, the impact metrics applied and how the due diligence and investment process is carried out. Millennials and tech will get special attentions across the future studies.

Acknowledgements. The authors acknowledge financial support from the H2020 FET project DOLFINS (grant no. 640772), and the Slovenian Research Agency (research core funding no. P2-103).

\section{References}

1. Blondel, V.D., Guillaume, J.L., Lambiotte, R., Lefebvre, E.: Fast unfolding of communities in large networks. J. Stat. Mech. Theor. Exp. 2008(10), 10008 (2008)

2. Eurosif: Investing investing in Europe: Extract from European SRI study 2014 (2014)

3. Fortunato, S.: Community detection in graphs. Phys. Rep. 486, 75-174 (2010)

4. Grčar, M., Cherepnalkoski, D., Mozetič, I., Kralj Novak, P.: Stance and influence of Twitter users regarding the Brexit referendum. Comput. Soc. Netw. 4, 6

5. Hirsch, J.E.: An index to quantify an individual's scientific research output. Proc. Natl. Acad. Sci. 16,569-16,572 (2005)

6. Höchstädter, A.K., Scheck, B.: Whats in a name: an analysis of impact investing understandings by academics and practitioners. J. Bus. Ethics 132(2), 449-475 (2015)

7. King, D., Ramirez-Cano, D., Greaves, F., Vlaev, I., Beales, S., Darzi, A.: Twitter and the health reforms in the english national health service. Health Policy 110(2), 291-297 (2013)

8. Lancichinetti, A., Fortunato, S.: Community detection algorithms: a comparative analysis. Phys. Rev. E 80(5), 056117 (2009)

9. Misuraca, G., Kucsera, C., Lipparini, F., Voigt, C., Radescu, R., et al.: Mapping and analysis of ICT-enabled social innovation initiatives promoting social investment in integrated approaches to the provision of social services: IESI knowledge map 2015. Technical Report, Joint Research Centre (Seville site) (2016)

10. Morgan Stanley: Investing with impact 2017 (2017)

11. Mozetič, I., Grčar, M., Smailović, J.: Multilingual Twitter sentiment classification: the role of human annotators. PLoS ONE 11(5), e0155036 (2016). https://doi.org/ 10.1371/journal.pone.0155036

12. Mudaliar, A., Schiff, H., Bass, R.: Annual impact investor survey 2016 (2016)

13. Newman, M.E.J.: Modularity and community structure in networks. Proc. Natl. Acad. Sci. USA 103(23), 8577-8582 (2006)

14. Riquelme, F., González-Cantergiani, P.: Measuring user influence on twitter: a survey. Inf. Process. Manag. 52(5), 949-975 (2016)

15. Sluban, B., Smailović, J., Battiston, S., Mozetič, I.: Sentiment leaning of influential communities in social networks. Comput. Soc. Netw. 2, 9 (2015). https://doi.org/ $10.1186 /$ s40649-015-0016-5 